\title{
Life Cycle Analysis of Endosymbiotic Algae in an Endosymbiotic Situation with Paramecium bursaria Using Capillary Flow Cytometry
}

\author{
Toshiyuki Takahashi
}

Department of Chemical Science and Engineering, National Institute of Technology, Miyakonojo College, Miyazaki 885-8567, Japan; mttaka@cc.miyakonojo-nct.ac.jp; Tel.: +81-986-47-1219; Fax: +81-986-47-1231

Academic Editor: Paul L. Chen

Received: 10 August 2017; Accepted: 6 September 2017; Published: 15 September 2017

\begin{abstract}
Along with algae as producers in ecosystems and industrial applications, some microalgae existing in special ecological niches through endosymbiosis with other organisms represent fascinating examples of biological evolution. Although reproducing endosymbiosis experimentally is difficult in many situations, endosymbiosis of several ongoing types is possible. Endosymbiosis in Paramecium bursaria is a particularly excellent model. Although many studies of $P$. bursaria have specifically examined infection processes such as the host recognition of symbionts, coordination of host-symbiont division, which has been explored for eukaryotic organelles, is worth pursuing. Evaluating the cell (life) cycle of algae is crucially important for algal applications. Flow cytometry (FCM) has been used to study cell cycles of several eukaryotic cells including microalgae. Microscopy, however, has been used mainly to study endosymbiosis, as with P. bursaria, because of their larger size than suitable cells for FCM with hydrodynamic focusing. Vast amounts of time have been expended for microscopic analysis. This review presents an approach using capillary FCM to elucidate the endosymbiosis of $P$. bursaria. Results reveal that endosymbiotic algae of $P$. bursaria finely adjust their cell cycle schedule with their comfortable host and show that a coincident endosymbiont-host life cycle is virtually assured in their endosymbiosis.
\end{abstract}

Keywords: endosymbiosis; microalgae; Chlorella; chlorophyll fluorescence; cell cycle; fluorescence microscopy; evolution

\section{Introduction}

Phytoplankton such as microalgae support and underpin aquatic ecosystems, contributing as ecosystem producers to the yields of both fish and shellfish. In addition to elucidating their role in aqueous ecosystems, evaluation of algae and other phytoplankton is necessary for industrial applications such as biofuel production [1-4], and for environmental surveys such as those of algal blooms $[5,6]$. Ascertaining the cell (life) cycle of algae is crucially important for every algal application because the rate of progression at the cell cycle of algae strongly affects algal health and integrity. Although several approaches have been used to examine the cell cycle in the life science field, FCM presents a standard and important technique to evaluate the cell (life) cycle of algae. It has been proposed as a quick and reliable tool for studying cell status and the cell cycle [6]. The algae life cycle is also a fascinating research topic because unicellular algae are convenient objects for flow cytometric characterization [6].

It is particularly interesting that some microalgae have occupied special ecological niches by establishing specific and symbiotic relations with other organisms, thereby offering fascinating examples of biological evolution. In fact, the functions descended from symbionts to the host organisms have been instrumental in advancing cell evolution [7]. For instance, photosynthesis occurs in nearly 
every algae and plants. However, red and green algae, as is true in land plants, are truly products of evolutionary results derived from primary endosymbiosis between a cyanobacterium (a photosynthetic prokaryote) and a colorless eukaryotic cell [8-11]. In addition to the clues related to aspects of biological evolution, production of artificial endosymbiosis such as photosynthetic animal cells might provide useful hints that can elucidate cell development. Nevertheless, reproducing endosymbiosis experimentally is difficult because almost all endosymbionts, including organelle-like symbionts, can no longer survive outside of a host cell.

Several endosymbioses aside from those completed endosymbioses described above are presently under examination, including those between freshwater eukaryotic hosts and eukaryotic algal symbionts in a protozoan Paramecium bursaria [12-16] and green hydra Hydra viridissima $[12,17,18]$ as generally known as $H$. viridis, and between marine eukaryotic hosts and unicellular algal symbionts in an anthozoan coral [12], marine sponges [19-23], a upside-down jellyfish Cassiopea xamachana [12], an ascidian Didemnum molle [12] and a type of sea slug Melibe engeli [24]. Several studies using microscopy have revealed that the ciliate protozoan P. bursaria harbors several hundreds of Chlorella-like algae in its cytoplasm $[7,25,26]$ (Figure 1A). Exposure of $P$. bursaria to specific chemicals such as a herbicidal paraquat [27] and the human neurotoxin acrylamide $[28,29]$ or incubation of P. bursaria in complete darkness [30] can turn the symbiotic association topsy-turvy. Such treatments eventually produce algae-free paramecia (Figure 1B). Here, herbicidal action of paraquat and acrylamide [29] against endosymbiotic algae and the ciliate hosts is related to production of reactive oxygen species. Unlike the sexual reproduction of $H$. viridis [18], sexual reproductive capability by conjugation of algae-free Paramecium is uninfluenced by the removal of endosymbionts [7] (Figure 1C,D). Growth of P. bursaria certainly produces advantages such as photosynthetic products from endosymbiotic algae, leading to their greater proliferation than that of algae-free Paramecium (Figure 1E). Their endosymbiotic algae are apparently unnecessary for the survival of their ciliate hosts, testifying that the algae-free strain of P. bursaria can increase uneventfully in culture media containing bait bacteria for P. bursaria, independently of the compatible algal partners for the ciliate hosts (Figure 1E). Several studies have described that exosymbiotic algae experimentally isolated from the ciliate hosts can increase independently from the hosts $[5,25]$. The expression "exosymbiotic alga" in this study denotes an experimentally cloned alga isolated from $P$. bursaria. Unlike organelles such as mitochondria derived from a eubacterium and chloroplasts from a cyanobacterium, exosymbiotic algae isolated from P. bursaria can self-manage their cell cycle pace. When the algae-free Paramecium is blended with exosymbiotic algae, the algae-free Paramecium takes algae and restores the symbiotic relation between endosymbionts and ciliate hosts to a natural and healthy state $[25,30,31]$. From these features, the endosymbiosis in $P$. bursaria is referenced as an excellent model for use in experimental endosymbiosis. These symbioses observed in P. bursaria are established by the following multistage processes [7]: (1) Intake or infection of symbionts into a host cell; (2) Appropriate recognition of ingesta or invaders as a symbiotic partner by the host cell; (3) Acceptance of them by the host, but not forced eviction of them by host phagocytosis; and (4) Stable establishment of endosymbiosis. Particularly, the establishment of endosymbiosis is related with the stability of the endosymbiotic algae cell cycle, which is controlled by each host cell. In fact, a single-cell analysis of $P$. bursaria using microscopy revealed that endosymbiont numbers double immediately before the host enters the division phase [15,30]. Consequently, endosymbionts must arrange their cell cycle schedule if changes in the culture conditions delay the generation time of P. bursaria. Although many symbiotic studies involving symbiosis in P. bursaria have specifically examined infection processes such as the recognition of appropriate symbionts by the host $[25,30]$, much less attention has been devoted to long-term stability in the endosymbiotic relation between the host and endosymbiotic algae. The coordination of host-symbiont division, like that done by eukaryotic organelles that have endosymbiotic evolutionary origin, is worth investigation $[7,32,33]$.

Microscopy has served as a common tool for analyses of $P$. bursaria endosymbiosis. A vast amount of time for obtaining data, however, has been expended for studies based on microscopic techniques. This review presents an approach for studying the endosymbiosis of P. bursaria using 
capillary FCM [34] and life cycle behavior between endosymbionts and the host [7]. With the addition of a more time-saving method using FCM than methods using microscopic techniques, this analysis demonstrates that endosymbiotic algae fine-adjust their cell cycle schedule with their comfortable host and indicates that a coincident life cycle between the endosymbiotic algae and the host is virtually assured in the endosymbiosis of P. bursaria [7].
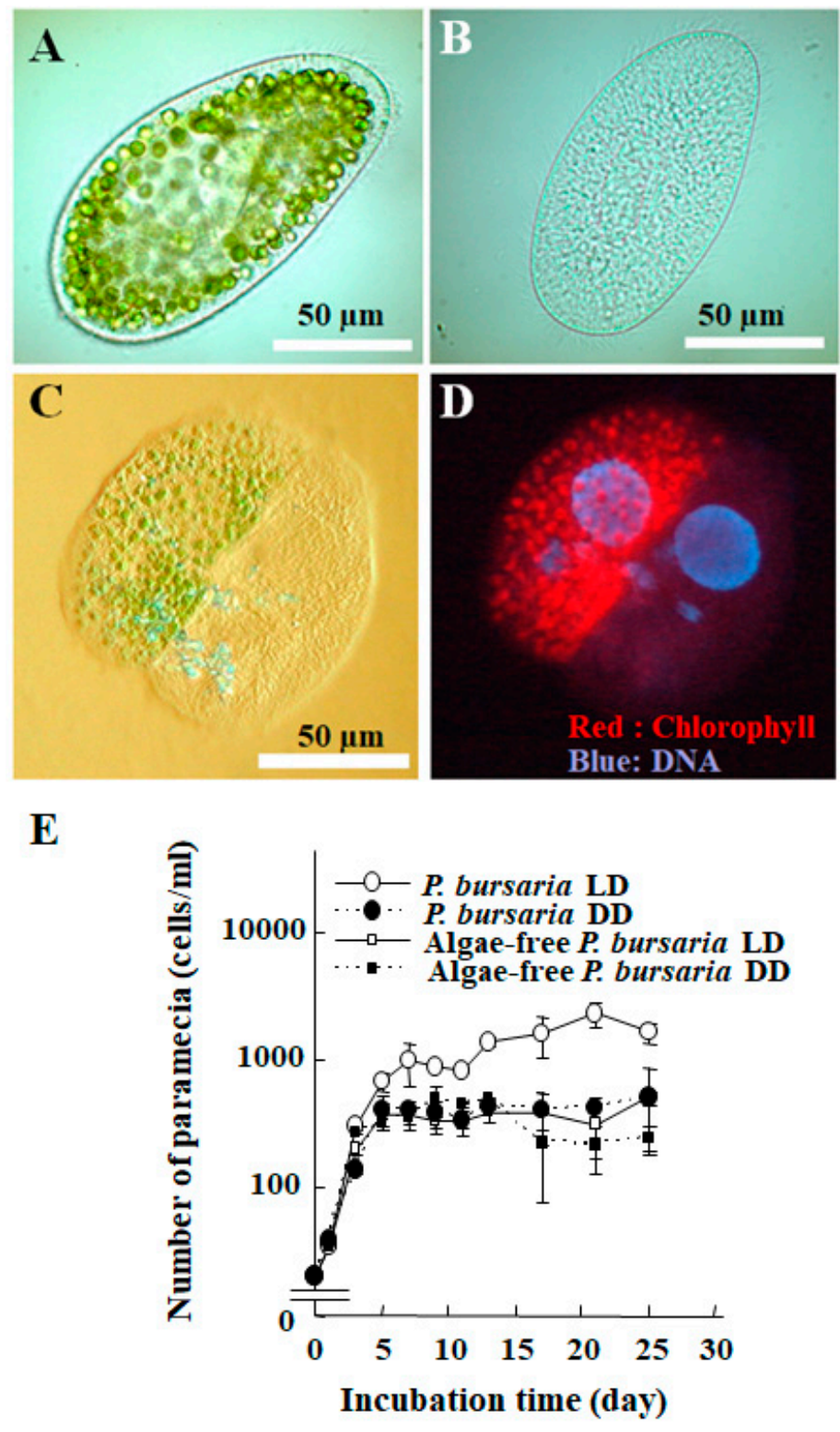

Figure 1. P. bursaria in a natural state and several experimental states. Photographs show P. bursaria with endosymbiotic algae in a natural state (A) and algae-free Paramecium (B) produced by treatment of $P$. bursaria with paraquat herbicide. Photographs $((\mathbf{C})$ a bright field image and $(\mathbf{D})$ the corresponding fluorescence image) show sexual conjugation of native $P$. bursaria with an algae-free strain of $P$. bursaria produced by exposure of a human neurotoxin acrylamide to $P$. bursaria. Red and blue fluorescence in the panel D respectively derive from endogenous chlorophyll of endosymbiotic algae and from DAPI-staining Paramecium nuclei. Here, panels A-D were referred from the literature [7]. (E) The graph depicts growth kinetics of algae-bearing P. bursaria cultured under an LD cycle (12 h light/12 h dark) (white circle), that under DD (constant dark) (black circle), algae-free P. bursaria under a LD cycle (white square), and alga-free cells under DD (black square) in media containing bait bacteria. The numbers of paramecia (average \pm S.D.) are shown over time. 


\section{Life Cycle of Endosymbionts in P. bursaria Host Cell Analyzed Using Microscopic Analysis}

Several ongoing plastid-acquisition types of endosymbiosis are observed in sacoglossan sea slugs such as Elysia chlorotica and E. timida [11,35-37], and in the marine ciliate Mesodinium rubrum [38-41]. However, they are defective in their ability to maintain permanent endosymbiosis. Their plastids derived from endosymbiosis, for instance, are not transmitted vertically. They do not undergo division in the sea slugs [11]. In contrast to the transient endosymbioses described above, the endosymbiosis in P. bursaria is apparently a coordinated endosymbiosis, with the result that endosymbiotic algae undergo cell division in P. bursaria host cells. They are subsequently transmitted to daughter cells. To maintain endosymbiosis permanently in P. bursaria, it is a crucially important task for the P. bursaria host cell to distribute endosymbionts equally to daughter cells during cytokinesis of $P$. bursaria. The prominent cellular motion of P. bursaria, rotational cytoplasmic streaming, changes through their cell cycle [15]. The microtubule-based cytoplasmic streaming [42] at their interphase circulates cytoplasmic granules and endosymbionts of P. bursaria in a constant direction [15,42], although the streaming is arrested at the division phase of $P$. bursaria [15]. The surcease at the division phase of $P$. bursaria might be related to allotment of cytoplasmic microtubules for microtubule-based nuclear division (Figure 2). In fact, cytoplasmic streaming is at least arrested during macronuclear division. It is noteworthy that their endosymbiotic algae proliferate only during the arrest of cytoplasmic streaming (Figure 3), even if artificial arrest of the streaming in paramecia occurs at the interphase by pressure or as the effect of a microtubule drug [15]. The endosymbionts do not more than double in number even if under conditions of arrested cytoplasmic streaming (Figure 3A) [15]. In fact, endosymbiotic algae in $P$. bursaria at the stationary phase and cytokinesis seldom divide, although algae undergoing cell division and autospores have been observed frequently during macronuclear division of $P$. bursaria (Figure 3B). Consequently, P. bursaria have mechanisms to maintain endosymbiosis for regulating the number of endosymbionts through the cell cycle.
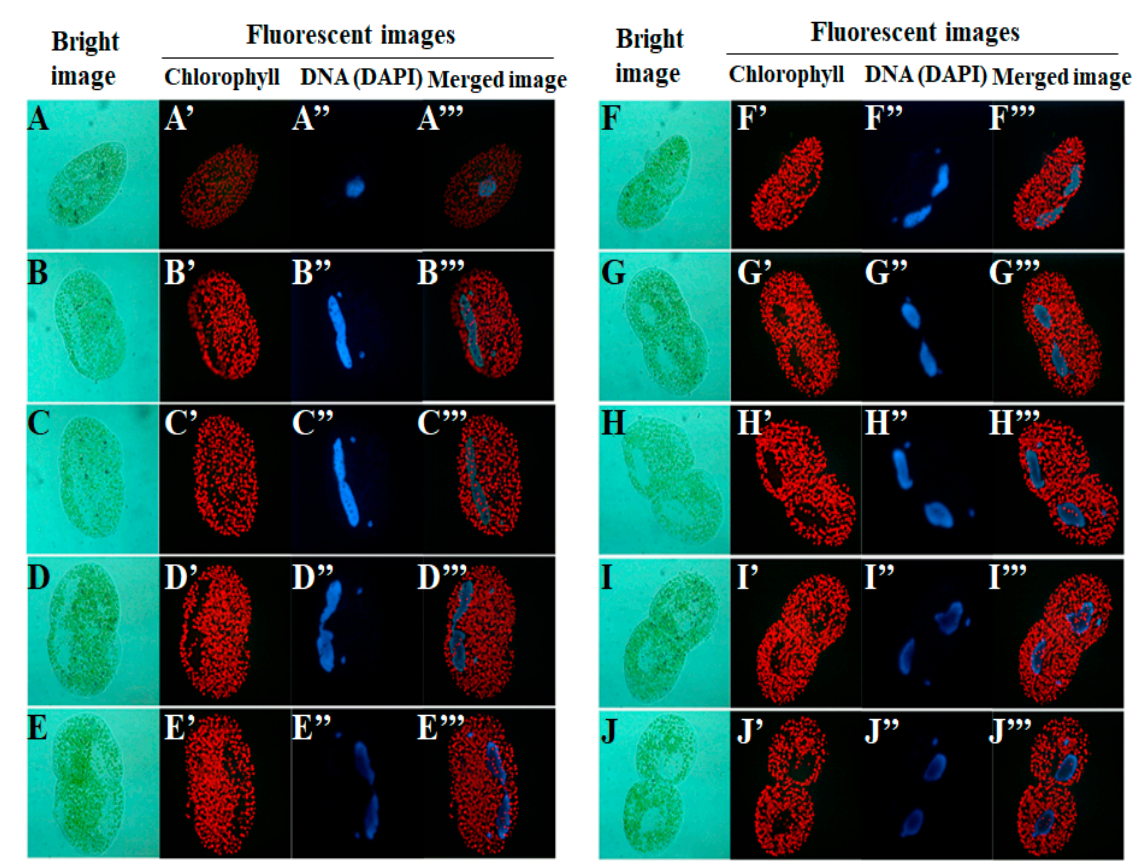

Figure 2. Morphological changes of P. bursaria through the host cell cycle. Photographs show P. bursaria from interphase (A) to late cytokinesis (J). In addition to bright field images at each stage, corresponding fluorescence images for chlorophyll of endosymbiotic algae and DAPI-staining Paramecium nuclei are shown. Here, parts (panels I and I"') of the photographs were referred from the literature [15]. Others present unpublished data from a study of the literature [15]. 
A

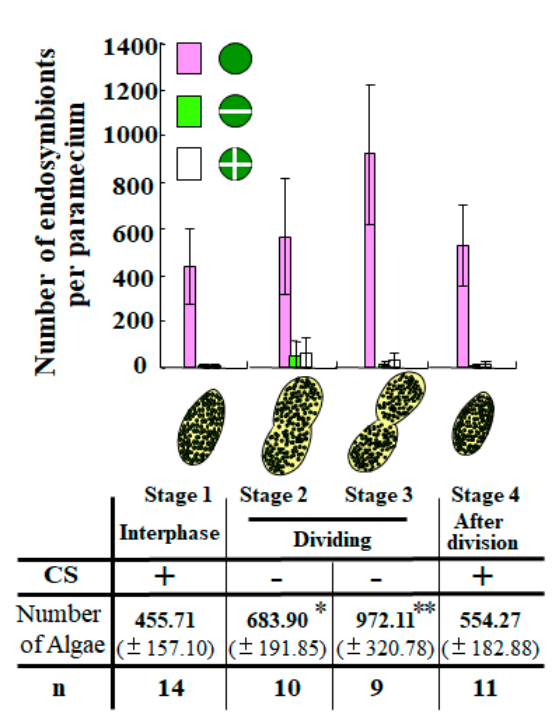

B

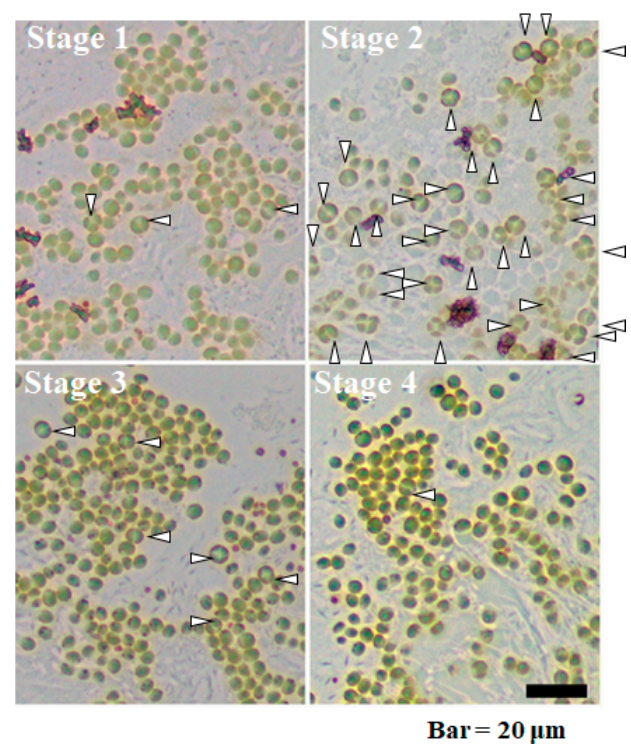

Figure 3. Cytoplasmic streaming of P. bursaria and the number of endosymbiotic algae in each host cell through the host cell cycle. (A) The bar graph shows the numbers of endosymbiotic algae in respective host cells (average \pm S.D.) at respective phases of the host cell cycle (stages 1-4). The endosymbionts are classified into a unicellular cell (purple), 2 (green), and 4 autospores (white) in this panel. The table presents whether cytoplasmic streaming of P. bursaria occurs (+) or not (-), and the total number of endosymbiotic algae in P. bursaria. Here, ${ }^{*}$ and ${ }^{* *}$ respectively denote significant differences with $t$-test, ${ }^{*} p<0.005$ and ${ }^{* *} p<0.001$ vs. the number of endosymbionts in a host cell at the interphase. Panel A was referred from the literature [15]. (B) Microphotographs at each phase of host cell cycle: arrowheads indicate endosymbiotic algae at 2 and 4 autospores. Scale bar, $20 \mu \mathrm{m}$. The panel presents unpublished data from a study of the literature [15].

Perceiving each life cycle of individual alga from several hundred endosymbionts in P. bursaria using microscopic operation alone is difficult work. To elucidate endosymbiosis between the P. bursaria host cell and endosymbiotic algae, developing some method to monitor the life cycle of endosymbionts in P. bursaria effectively and sensitively is crucially important.

\section{Analysis for Studying Endosymbiosis of P. bursaria Using Capillary FCM}

\subsection{Capillary Type Flow Cytometry, Not Hydrodynamic Focusing with Sheath Fluid, to Detect Intact Paramecium Cells}

Over the last several decades, FCM has served as a powerful and valuable tool for studies in areas such as cell biology, microbiology, protein engineering, and healthcare [2]. FCM has functions to conduct several procedures such as cell counting, biomarker detection, cell cycle analysis, and cell sorting. On studying algae, FCM in analogy with spectrofluorometry can pick up chlorophyll fluorescence of algae, and can evaluate several properties of individual alga [6]. Many commercially available flow cytometers use hydrodynamic focusing with sheath flow to analyze particulate analytes such as floating cells. Hydrodynamic focusing with sheath fluid enables standard flow cytometers to select single cell one-by-one from samples containing cells of different types (panel 1 in Figure 4A). These flow cytometers with flow cell tips having common diameters of 50-72 $\mu \mathrm{m}$ [43] are optimized for suspended cells with 1-30 $\mu \mathrm{m}$ diameter [7,44]. Therefore, the use of a typical nozzle in commercial FCM imposes important limitations and challenges for the sorting and analysis of larger cells [45]. For that reason, few FCM techniques using hydrodynamic focusing have been used to study complex systems between eukaryotic host cells and small eukaryotic endosymbionts such as microalgae [7], which has cell width 
and length of ca. $50 \mu \mathrm{m}$ and 120-150 $\mu \mathrm{m}$ more than cells for standard FCM. In fact, a few reports of the literature describe FCM analysis of intact $P$. bursaria host cells using an instrument nozzle of a special size: $200 \mu \mathrm{m}$ diameter [46]. In terms of morphological usability of microalgae for FCM, more exosymbiotic algae isolated from P. bursaria than the host cells have been studied and analyzed using FCM [5,6,47]. Many data obtained only from their algae, however, are entirely inadequate to clarify the mechanisms underlying endosymbiosis or the life cycle of endosymbionts remaining in P. bursaria because these exosymbiotic algae have already been disengaged from control by the host [7,34]. To evaluate and understand the cell (life) cycle dynamics of endosymbiotic algae in P. bursaria but not exosymbiotic algae, one must detect and evaluate intact $P$. bursaria host cells using FCM.

A

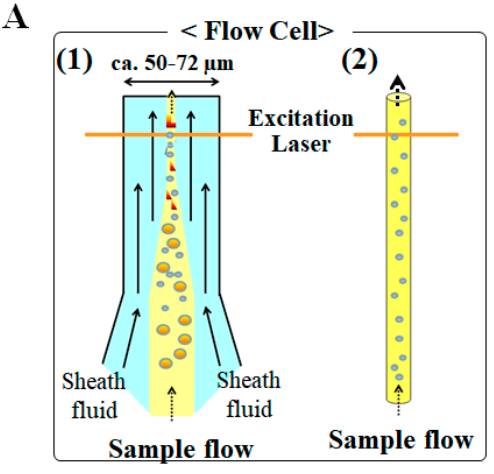

C

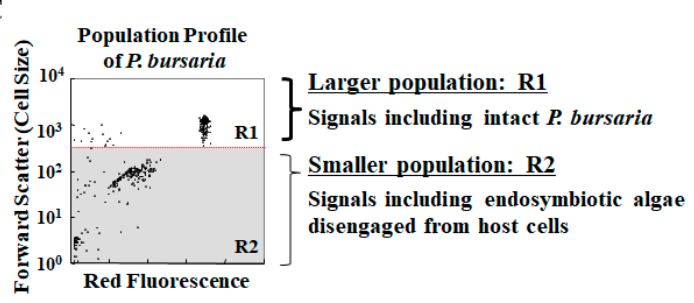

B

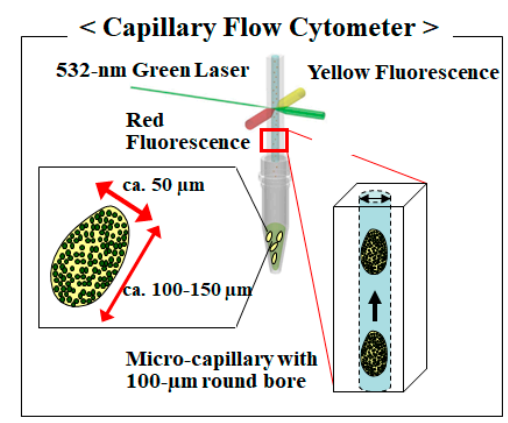

D

Figure 4. Analytical overview of P. bursaria using capillary FCM. (A) Diagrammatic view of a flow cell to pick up single cells one-by-one for flow cytometers. Panels (1) and (2) respectively present a conventional flow cytometer with hydrodynamic focusing and a capillary flow cytometer. (B) Overview of the system using a capillary FCM. Cells that had gotten through a rectangular capillary are measured using a capillary FCM. This system can detect forward scatter signals, chlorophyll fluorescence in the red fluorescence channel $(680 / 30 \mathrm{~nm}$ BP filter), and fluorescence in the yellow channel (576/28 nm BP filter) simultaneously. (C) Example of FCM measurements of P. bursaria fixed with $5 \%(v / v)$ formalin using capillary FCM: the scatter plot shows the detection of intact $P$. bursaria host cells (R1) and endosymbiotic algae (R2) disengaged from P. bursaria. (D) This microscopic image shows samples collected from the waste bottle of the capillary flow cytometer. Panels (B-D) were referred from the literature [34], but were modified.

To characterize $P$. bursaria using FCM, recent studies have demonstrated that microcapillary FCM (panel 2 in Figure 4A), not hydrodynamic focusing, can detect intact P. bursaria [7,34]. For instance, the Muse ${ }^{\mathrm{TM}}$ Cell Analyzer (Merck Millipore Corp., Hayward, CA, USA), which has a photodiode for detection of forward scatter signals and a $680 / 30 \mathrm{~nm}$ band pass (BP) filter suitable for chlorophyll fluorescence [34] (Figure 4B), can detect not only endosymbiotic algae but also intact P. bursaria host cells through a rectangular capillary with a $100-\mu \mathrm{m}$ round bore (Figure $4 \mathrm{C}$ ). As shown in Figure 4C, two distinct populations (designated as R1 and R2) from P. bursaria cells are detected using capillary FCM. Scattered signals in the R1 region (Figure 1C) signify intact $P$. bursaria cells possessing endosymbiotic algae. In contrast to signals in the R1 region, the remarkably large number of smaller signals in the R2 (Figure 1C) shows endosymbionts released from some broken P. bursaria host cells [34]. For comparison, pure-cultured exosymbiotic algae isolated from P. bursaria, but not algae disengaged from P. bursaria, were also detected only in R2 (data not shown) [34]. When cells that passed through 
the capillary were collected from the waste liquid bottle of an instrument and were observed, they were found to include several morphologically intact $P$. bursaria (Figure 4D) [34]. According to a report of an earlier study [34], the rate of passage of intact P. bursaria cells through the capillary was $79 \pm 9.9 \%$. P. bursaria has several hundred endosymbiotic algae (ca. 400-500 endosymbionts/Paramecium) in the cytoplasm [15,27]. Therefore, it is noteworthy that major signals as the overall signals in R1 plus R2 are apparently from endosymbiotic algae disengaged from host cells, even if a few host cells are broken (Figure 4C). These results demonstrated that at least several intact $P$. bursaria cells can pass through the measurement point irradiated by an excitation laser. Consequently, this system is expected to be a high-potency tool for studies of endosymbioses such as that shown in P. bursaria [7,34].

\subsection{Detection of Difference in Cell Cycle of P. bursaria Host Cells Using Capillary FCM}

As presented in Figure 2, P. bursaria apparently changes its shape through the cell cycle. Figure 5A depicts $P$. bursaria at the interphase. Figure $5 \mathrm{~B}, \mathrm{C}$ present $P$. bursaria cells at the nuclear division phase. Figure 5D portrays Paramecium at cytokinesis [7]. Unlike microscopic analysis, FCM is a population analysis. Data analyzing the P. bursaria population includes details about both host cells at the interphase and division phase. Before evaluation of the life cycle dynamics of endosymbiotic algae in P. bursaria, it is important to ascertain whether a capillary FCM can detect differences in the cell cycle of $P$. bursaria host cells and whether data from a capillary FCM enables us to characterize the cell cycle of host cells. Almost all available test cells, including mammalian, protozoa, and bacteria, proliferate through the processes of a logarithmic growth phase (an exponential growth phase), stationary phase, and finally result in death phase because of nutrient depletion and the accumulation of metabolic waste in culture media. Consequently, P. bursaria host cells at the division phase (Figure 5B-D) must be observed more frequently in the Paramecium culture at the logarithmic phase than in cultures at other phases. The growth of P. bursaria host cells was first tracked (black circle in Figure 5E) [7]. Later, the generation time (white squares in Figure 5E) was calculated from the total number of host cells using the following Equations (1)-(3) [7]:

$$
\begin{gathered}
N=N_{0} \times 2^{(t / g)} \\
\log N=\log \left(N_{0} \times 2^{(t / g)}\right) \\
g=(t \times \log 2) / \log \left(N / N_{0}\right)
\end{gathered}
$$

Here, $t$ and $g$ respectively represent the incubation time $(\mathrm{h})$ and the generation time $(\mathrm{h})$. Moreover, $N$ and $N_{0}$ respectively denote the numbers of paramecia (cells $/ \mathrm{mL}$ ) after incubation and the initial cell density of paramecia (cells $/ \mathrm{mL}$ ) before incubation. Consequently, $t / g$ stands for the cell division frequency. From this graph (Figure 5E), the culture time from 1 day to 4 days of incubation was regarded as the logarithmic phase of host cells, whereas the culture time at 7-day of incubation was regarded as the early stationary phase. In response to an entry to stationary phase of $P$. bursaria, the generation time was extended gradually from ca. $16 \mathrm{~h}$ to more than $24 \mathrm{~h}$ simultaneously with the reduction of the number of P. bursaria division times [7]. To detect the cell cycle-dependent cell morphology of host cells using capillary FCM, P. bursaria at each phase was subjected to capillary FCM (Figure 5F). Based on the gating strategy portrayed in Figure $4 \mathrm{C}$, signals of host cells alone were extracted from data obtained using capillary FCM. The reconstructed result (Figure 5F) revealed three distinguishable populations detected from forward scatter signals [7]. Each is related to the cell size. The populations of small cells of P. bursaria are host ciliates shortly after Paramecium cell division (dotted line, $A_{D}$ in Figure 5F), cells at cytoplasmic fission (cytokinesis) as shown in Figure $5 \mathrm{D}\left(\mathrm{B}_{\mathrm{D}}\right.$ in Figure $5 \mathrm{~F}$ ), and intermediary cell sizes at the interphase or karyokinesis (Int in Figure 5F). Results show that capillary FCM can detect cell-cycle dependent changes and other subtle changes of P. bursaria at the microscopic level. Moreover, unlike conventional FCM with hydrodynamic focusing, capillary FCM need not have any particular size of nozzle to pick up large cells such as P. bursaria host cells. Capillary FCM might contribute to many time-saving and sensitive procedures to advance the study of symbiosis. 

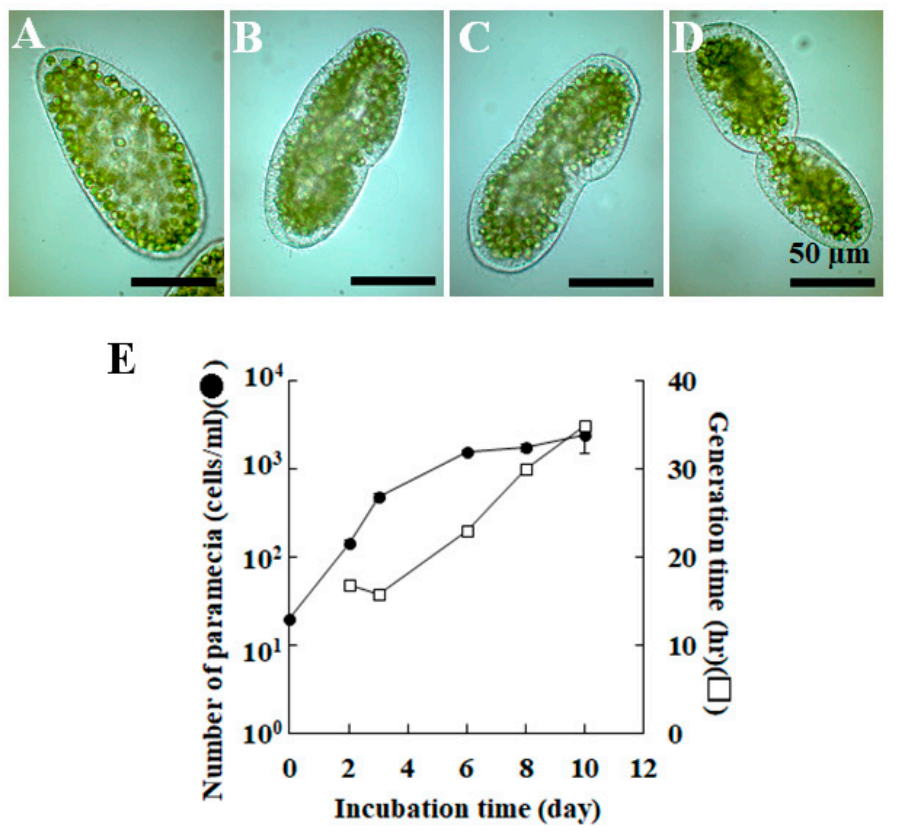

$\mathbf{F}$

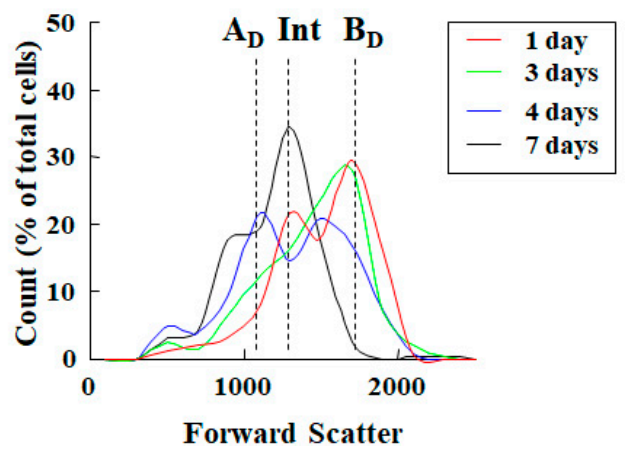

Figure 5. Growth dynamics of P. bursaria host cells and its detection using capillary FCM. (A-D) Micrographs of P. bursaria at interphase and division phase are shown. (E) Chronologic population dynamics of $P$. bursaria host cells (black circle) were tracked over time. The generation time (white circle) estimated from the number of P. bursaria is also shown. (F) Data obtained with P. bursaria are shown as forward scatter signals (FSS) vs. count (\% of total signals for intact $P$. bursaria cells). As described in the literature [7], dotted lines in panel F display each discernible peak size of P. bursaria. Each dotted line respectively shows the group of small Paramecium cells shortly after Paramecium cell division $\left(A_{D}\right)$, that of cells in the process of cytokinesis $\left(B_{D}\right)$, and those of the intermediary cell sizes at both the interphase and in the process of karyokinesis (Int). Panels (A-F) were referred from the literature [7].

3.3. Cooperative Population Dynamics of Endosymbiotic Algae in P. bursaria Host Cells in Response to the Cell Cycle of Host Cells

It remains poorly understood how endosymbionts act in accordance with the culture-condition-dependent behaviors of P. bursaria host cells, as presented in Figure 5E. Technical advantages of capillary FCM over other conventional techniques include the concurrent evaluation of both endosymbionts and their P. bursaria host cells [7]. To evaluate the optical characteristics of endosymbiotic algae throughout the population dynamics of $P$. bursaria as presented in Figure 5E, P. bursaria at different phases (Figure 5F) was subjected to capillary FCM. Based on the gating strategy portrayed in Figure 4C, signals of endosymbionts were extracted from data obtained using capillary FCM. The results are expressed as scatter plots for the size (forward scatter) vs. chlorophyll 
contents (red fluorescence intensity) (Figure 6A) [7]. Results obtained from capillary FCM exhibit that the variation of endosymbiotic algae changed with the culture duration of P. bursaria. Gerashchenko et al. demonstrated that the cell size and chlorophyll contents of microalgae such as Chlorella sp. and exosymbiotic algae are closely correlated with the algal cell cycle $[5,6]$. Considering the algal cell cycle, the distribution of endosymbionts depicted in Figure 6A was categorized into three populations: a population of algae with both small size and high chlorophyll contents (designated as region I) for a growing alga, a population of both large size and high chlorophyll contents (region II) for those including autospores, and a population of low chlorophyll contents (region III) for those of a unicellular alga immediately after division (Figure 6B) [7]. Using categorization of endosymbiotic algae, the algal ratio in each region (regions I-III) was estimated and compared for each culture duration (0-7 days) (Figure 6C). These analyses revealed that both ratios of regions I and II increased incrementally with incubation time, whereas the ratio of region III decreased.

A
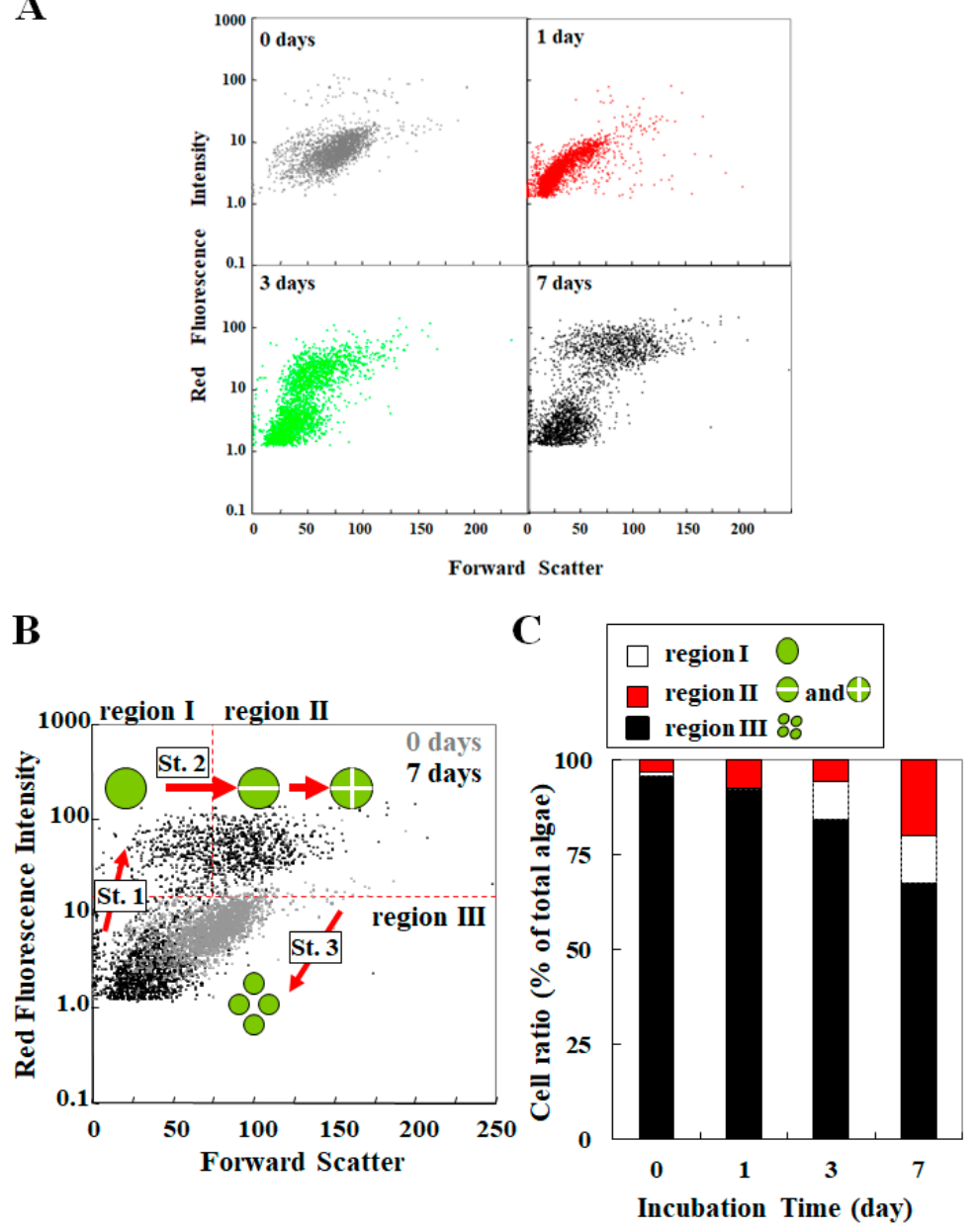

Figure 6. Demographic dynamics of endosymbiotic algae in P. bursaria using capillary FCM. (A) Scatter plots for forward scatter signals (FSS) vs. red fluorescence intensity are shown using data obtained from $P$. bursaria at different growth phases. It is noteworthy that the displayed signals include only data from endosymbiotic algae, but not from intact $P$. bursaria host cells. (B) A result of comparison among distributional patterns of endosymbionts is portrayed culture term by culture term. Based on algal optical properties related to the algal cell cycle, the distributional patterns of endosymbionts are classified into three populations (regions I-III). Here, labels denote the St. 1, "growth" stage; St. 2, "ripening" stage; and St. 3, "division and autospore liberation" stages. (C) Chronological changes of algal distribution patterns are estimated as the composite bar chart at each incubation time of P. bursaria. These panels (A-C) were referred from the literature [7]. 
The ratio of each cell cycle phase at some instant (Figure 6C) is related closely to the actual duration of each cell cycle phase in analogy with culture-condition-dependent prolongation of the generation time in P. bursaria (Figure 5E). The present study compared the chronological population changes of endosymbiotic algae in P. bursaria with the host generation time (Figure 7). When P. bursaria host cells were at the exponential growth phase, the data (Figure 7) [7] show that endosymbiotic algae of regions I and II divide instantly and show that a smooth flow of endosymbiotic algae occurred from both algae at the growth phase (regions I) and the division phase (regions II) to algae at the autospore liberation phase (region III) (upper panels in Figure 8). In contrast, data obtained from P. bursaria at the early stationary phase show that endosymbiotic algae of regions I and II divide at a crawl: a slow flow of endosymbiotic algae occurs from algae at the division phase (regions II) to algae at the autospore liberation phase (region III) (lower panels in Figure 8). Endosymbiotic algae in P. bursaria apparently behave similarly to chloroplasts as photosynthetic apparatus because they contribute to the nutritional benefits of host cells (Figure 1E). Regarded in terms of features, the relation between the Paramecium host cells and the endosymbionts is similar to that between a phototrophic eukaryote and chloroplast(s). Many plastid division genes and proteins have been relocated evolutionarily to the eukaryotic host nucleus through endosymbiotic gene transfer (EGT) events [7,32,33,48-50]. The synchronous division between chloroplasts and each eukaryotic host cell is achieved in most algal species such as red and green algae, and in land plants in the following manner: each host cell dominantly regulates expression of the nucleus-encoded plastid division genes and proteins. Although organelles such as chloroplasts cannot become self-sustaining outside of an eukaryotic cell, exosymbiotic algae isolated from $P$. bursaria can proliferate independently from the host ciliate $[5,25,47]$. Endosymbiotic algae of $P$. bursaria, unlike organelles such as chloroplasts, are expected to be able to self-manage their cell cycle pace even if they remain in the host Paramecium. From several single-cell analyses of $P$. bursaria, these studies using microscopy have clarified that a host cell of $P$. bursaria strictly modulates the number of endosymbiotic algae [15,51] (Figure 3). This study using capillary FCM also captures the feature of the cell-cycle cooperative dynamics between the host Paramecium and the endosymbiotic algae (Figures 7 and 8). In spite of the self-organized potential of endosymbiotic algae, they realize the necessity of hastening or slowing their cell cycle schedule with their host cell cycle in one way or another. These cooperative cell cycle dynamics between the host and endosymbiotic algae might support the synchronization of chronological behaviors between endosymbionts and their Paramecium host cell even if such a change delays the host cell generation time.

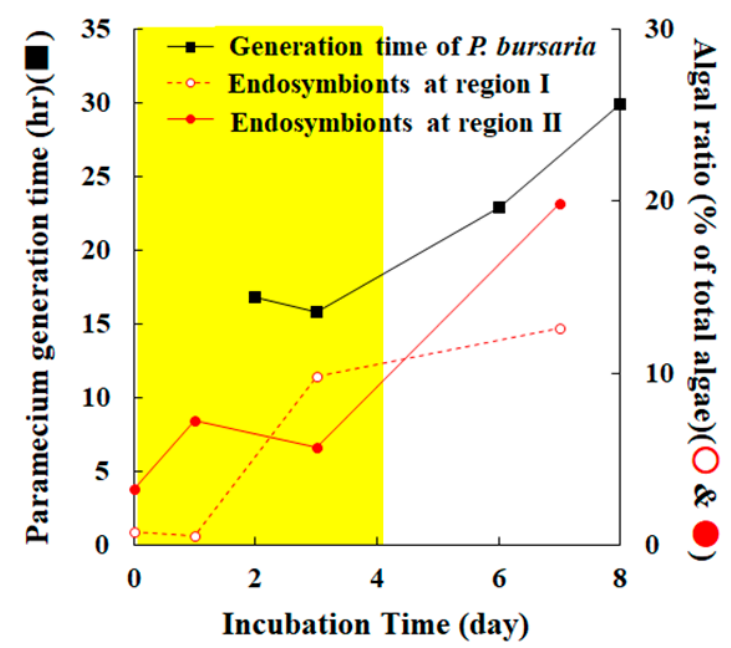

Figure 7. Entrainment of chronological behaviors between endosymbionts and their host paramecia. Host generation times (Figure 5E) and the chronological group dynamics of endosymbiotic algae in P. bursaria (Figure 6C) were compared. Yellow and white areas in the graph respectively represent the duration for the exponential growth phase and the initial stationary phase of P. bursaria. The figure was referred from the literature [7]. 


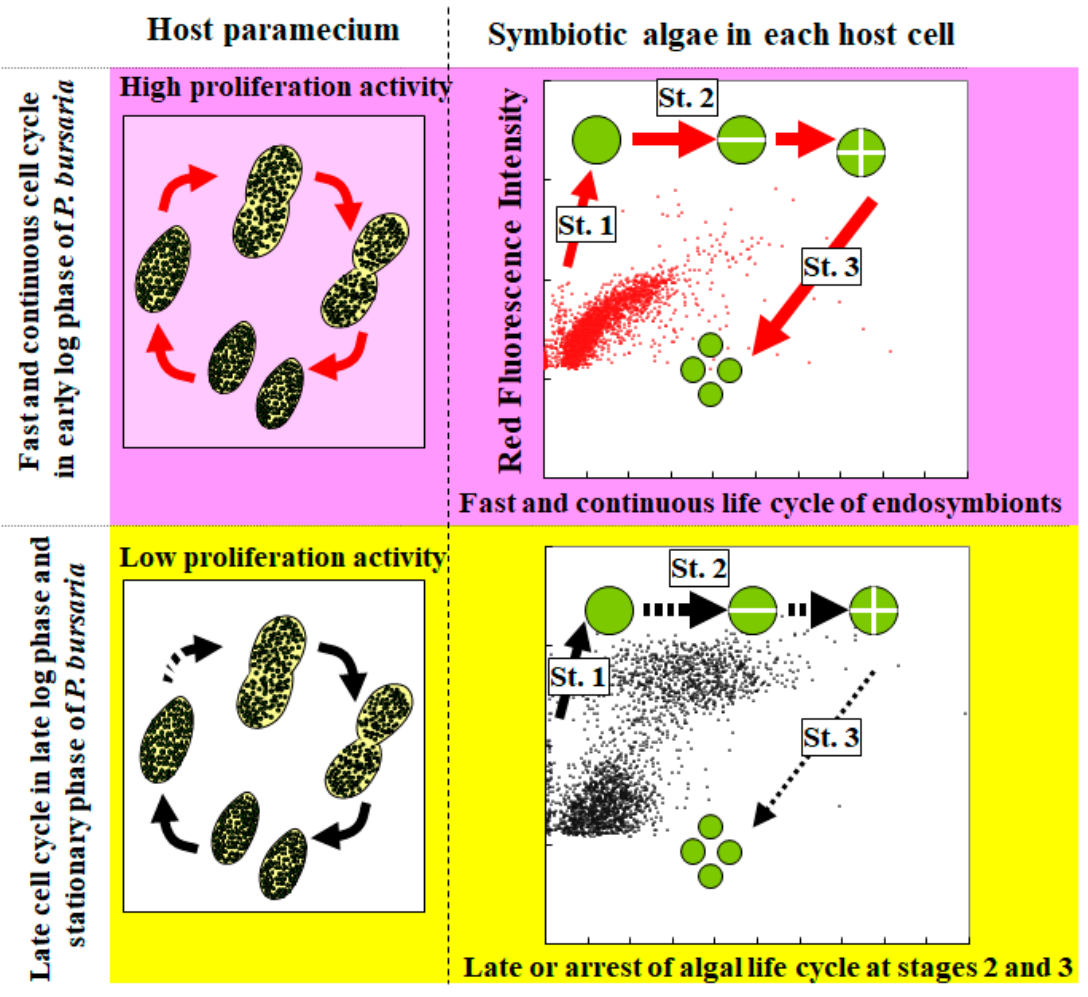

Figure 8. Cooperative dynamics of cell cycle between endosymbiotic algae and their host Paramecium. When the host cells are at the logarithmic growth phase and have high proliferation activity, endosymbiotic algae divide instantly. Then the smooth transition of endosymbionts occurs from algae at the growth and division phases to daughter algae (upper panels) (designated solid arrows). In contrast, endosymbiotic algae divide at a crawl when the host cells are at the early stationary phase and have low proliferation activity. Subsequently, a slow transition of endosymbionts occurs from algae at the division phase to daughter algae (lower panels) (indicated by dotted arrows).

\section{Conclusions}

Complex symbiosis models such as $P$. bursaria and H. viridissima, which are representative symbiosis models, are sufficiently larger than suitable cells for conventional FCM with hydrodynamic focusing. For just that reason, examination of symbiosis models such as those described above is difficult when done directly using conventional FCM. Unlike conventional FCM with hydrodynamic focusing, capillary FCM not only detects intact P. bursaria (Figure 4) but also discriminates a subtle shape change of the host cells (Figure 5). Moreover, the technique using capillary FCM can evaluate the life cycle dynamics of endosymbionts in the host cells simultaneously (Figure 6). Eventually, this technique can capture features by which the endosymbionts act in concert with culture-condition-dependent behaviors of the host cells by arranging their cell cycle schedule accordingly (Figures 5-8). Moreover, this technique reveals that a coincident life cycle between the endosymbiotic algae and the Paramecium host cell is virtually assured in the P. bursaria symbiosis system. In addition to detecting endogenous fluorescence of their endosymbiotic algae, the combination of fluoresceinated antibodies to cell-cycle regulatory proteins and the capillary FCM might provide invaluable insights to support symbiosis studies. Taken together, the evidence shows that this technique might elucidate why and how the number of endosymbionts in P. bursaria before the host division is approximately equal to their number after division.

Acknowledgments: This research was partly supported by Grants-in-Aid for Exploratory Research from the Japan Society for the Promotion of Science (KAKENHI Grant Nos. 23658280 and 17K05955). 
Author Contributions: Toshiyuki Takahashi designed and developed the approach to evaluate cell cycle of P. bursaria using capillary FCM. Toshiyuki Takahashi prepared and improved the paper.

Conflicts of Interest: The author has no conflict of interest, financial or otherwise, related to this study.

$\begin{array}{ll}\text { Abbreviations } \\ \text { FCM } & \text { flow cytometry } \\ \text { LD } & \text { light/dark cycle } \\ \text { DD } & \text { constant dark } \\ \text { DAPI } & 4^{\prime} \text {,6-diamidino-2-phenylindole } \\ \text { S.D. } & \text { standard deviation } \\ \text { BP } & \text { band pass } \\ \text { FSS } & \text { forward scatter signals } \\ \text { EGT } & \text { endosymbiotic gene transfer }\end{array}$

\section{References}

1. Spolaore, P.; Joannis-Cassan, C.; Duran, E.; Isambert, A. Commercial Applications of Microalgae. J. Biosci. Bioeng. 2006, 101, 87-96. [CrossRef] [PubMed]

2. Takahashi, T. Quality Assessment of Microalgae Exposed to Trace Metals Using Flow Cytometry. In Superfood and Functional Food-Development of Superfood and Its Role in Medicine; Shiomi, N., Waisundara, V.Y., Eds.; InTechOpen: Rijeka, Croatia, 2017; pp. 29-45.

3. Arashida, R. Characteristics of the microalgae Euglena and its applications in foods and ecological fields. Jpn. Soc. Photosynth. Res. 2012, 22, 33-38.

4. Chisti, Y. Biodeisel from microalgae. Biotechnol. Adv. 2007, 25, 294-306. [CrossRef] [PubMed]

5. Gerashchenko, B.I.; Kosaka, T.; Hosoya, H. Optical Compartmentation of Vegetating Algae Species as a Basis for Their Growth-Specific Characterization. Cytometry 2002, 48, 153-158. [CrossRef] [PubMed]

6. Gerashchenko, B.I.; Takahashi, T.; Kosaka, T.; Hosoya, H. Life Cycle of Unicellular Algae. Curr. Protoc. Cytom. 2010, 52. [CrossRef]

7. Takahashi, T. Simultaneous Evaluation of Life Cycle Dynamics between a Host Paramecium and the Endosymbionts of Paramecium bursaria Using Capillary Flow Cytometry. Sci. Rep. 2016, 6, 31638. [CrossRef] [PubMed]

8. Reyes-Prieto, A.; Weber, A.P.M.; Bhattacharya, D. The Origin and Establishment of the Plastid in Algae and Plants. Annu. Rev. Genet. 2007, 41, 147-168. [CrossRef] [PubMed]

9. Zimorski, V.; Ku, C.; Martin, W.F.; Gould, S.B. Endosymbiotic theory for organelle origins. Curr. Opin. Microbiol. 2014, 22, 38-48. [CrossRef] [PubMed]

10. De Vries, J.; Stanton, A.; Archibald, J.M.; Gould, S.B. Streptophyte Terrestrialization in Light of Plastid Evolution. Trends Plant Sci. 2016, 21, 467-476. [CrossRef] [PubMed]

11. Rumpho, M.E.; Pelletreau, K.N.; Moustafa, A.; Bhattacharya, D. The making of a photosynthetic animal. J. Exp. Biol. 2011, 214, 303-311. [CrossRef] [PubMed]

12. Muscatine, L.; Karakashian, S.J.; Karakashian, M.W. Soluble extracellular products of algae symbiotic with a ciliate, a sponge and a mutant Hydra. Comp. Biochem. Physiol. 1967, 20, 1-6. [CrossRef]

13. Ziesenisz, E.; Reisser, W.; Wiessner, W. Evidence of de novo synthesis of maltose excreted by the endosymbiotic Chlorella from Paramecium bursaria. Planta 1981, 153, 481-485. [CrossRef] [PubMed]

14. Summerer, M.; Sonntag, B.; Sommaruga, R. An experimental test of the symbiosis specificity between the ciliate Paramecium bursaria and strains of the unicellular green alga Chlorella. Environ. Microbiol. 2007, 9, 2117-2122. [CrossRef] [PubMed]

15. Takahashi, T.; Shirai, Y.; Kosaka, T.; Hosoya, H. Arrest of cytoplasmic streaming induces algal proliferation in green paramecia. PLoS ONE 2007, 2, e1352. [CrossRef] [PubMed]

16. Takahashi, T.; Nagasaki, A. Energy Production Using Microalgae Secreting Carbohydrates. J. Environ. Conserv. Eng. 2011, 40, 662-665.

17. Fishman, Y.; Zlotkin, E.; Sher, D. Expulsion of Symbiotic Algae during Feeding by the Green Hydra-A Mechanism for Regulating Symbiont Density? PLoS ONE 2008, 3, e2603. [CrossRef] [PubMed] 
18. Matthias, H.; Frederike, A.E.; Kathrin, N.; Thomas, C.B. The Hydra viridis/Chlorella symbiosis. Growth and sexual differentiation in polyps without symbionts. Zoology 2003, 106, 101-108.

19. Taylor, D.L. The Nutritional Relationship of Anemonia sulcata (PENNANT) and Its Dinoflagellate Symbiont. J. Cell Sci. 1969, 4, 751-762. [PubMed]

20. Weis, V.M.; Reynolds, W.S.; deBoer, M.D.; Krupp, D.A.A. Host-symbiont specificity during onset of symbiosis between the dinoflagellates Symbiodinium spp. and planula larvae of the scleractinian coral Fungia scutaria. Coral Reefs 2001, 20, 301-308. [CrossRef]

21. Rowan, R. Thermal adaptation in reef coral symbionts. Nature 2004, 430, 742. [CrossRef] [PubMed]

22. Richier, S.; Sabourault, C.; Courtiade, J.; Zucchini, N.; Allemand, D.; Furla, P. Oxidative stress and apoptotic events during thermal stress in the symbiotic sea anemone, Anemonia viridis. FEBS J. 2006, 273, 4186-4198. [CrossRef] [PubMed]

23. Bucher, M.; Wolfowicz, I.; Voss, P.A.; Hambleton, E.A.; Guse, A. Development and Symbiosis Establishment in the Cnidarian Endosymbiosis Model Aiptasia sp. Sci. Rep. 2016, 6, 19867. [CrossRef] [PubMed]

24. Burghardt, I.; Wägele, H. The symbiosis between the 'solar-powered' nudibranch Melibe engeli Risbec, 1937 (Dendronotoidea) and Symbiodinium sp. (Dinophyceae). J. Molluscan Stud. 2014, 80, 508-517. [CrossRef]

25. Nishihara, N.; Horiike, S.; Takahashi, T.; Kosaka, T.; Shigenaka, Y.; Hosoya, H. Cloning and characterization of endosymbiotic algae isolated from Paramecium bursaria. Protoplasma 1998, 203, 91-99. [CrossRef]

26. Hoshina, R.; Kamako, S.; Imamura, N. Phylogenetic Position of Endosymbiotic Green algae in Paramecium bursaria Ehrenberg from Japan. Plant Boil. (Stuttg.) 2004, 6, 447-453. [CrossRef] [PubMed]

27. Hosoya, H.; Kimura, K.; Matsuda, S.; Kitaura, M.; Takahashi, T.; Kosaka, T. Symbiotic Algae-free Strains of the Green Paramecium Paramecium bursaria Produced by Herbicide Paraquat. Zool. Sci. 1995, 12, 807-810. [CrossRef]

28. Takahashi, T.; Yoshii, M.; Kawano, T.; Kosaka, T.; Hosoya, H. New bioassay for the assessment of acrylamide toxicity using a green Paramecium. Toxicol. In Vitro 2005, 19, 99-105. [CrossRef] [PubMed]

29. Takahashi, T.; Yoshii, M.; Kosaka, T.; Hosoya, H. The Effect of Acrylamide Inducing the Reduction of Nitrobluetetrazolium on the Ciliate and Human Cultured Cells. ITE Lett. Batter. New Technol. Med. 2005, 6, 50-58.

30. Kodama, Y.; Fujishima, M. Symbiotic Chlorella sp. of the ciliate Paramecium do not prevent acidification and lysosomal fusion of the host digestive vacuoles during infection. Protoplasma 2005, 225, 191-203. [CrossRef] [PubMed]

31. Nishihara, N.; Takahashi, T.; Kosaka, T.; Hosoya, H. Characterization of Symbiotic Alagae-free Strains of Paramecium bursaria Produced by the Herbicide Paraquat. J. Protozool. Res. 1996, 6, 60-67.

32. Miyagishima, S.; Kabeya, Y. Chloroplast division: Squeezing the photosynthetic captive. Curr. Opin. Microbiol. 2010, 13, 738-746. [CrossRef] [PubMed]

33. Miyagishima, S.; Suzuki, K.; Okazaki, K.; Kabeya, Y. Expression of the Nucleus-Encoded Chloroplast Division Genes and Proteins Regulated by the Algal Cell Cycle. Mol. Biol. Evol. 2012, 29, 2957-2970. [CrossRef] [PubMed]

34. Takahashi, T. Direct Evaluation of Endosymbiotic Status in Paramecium bursaria Using a Capillary Flow Cytometry. Cytom. Part A 2014, 85, 911-914. [CrossRef] [PubMed]

35. Dorrell, R.G.; Howe, C.J. What makes a chloroplast? Reconstructing the establishment of pohotosynthetic symbioses. J. Cell Sci. 2012, 125, 1865-1875. [CrossRef] [PubMed]

36. De Vries, J.; Woehle, C.; Christa, G.; Wägele, H.; Tielens, A.G.; Jahns, P.; Gould, S.B. Comparison of sister species identifies factors underpinning plastid compatibility in green sea slugs. Proc. R. Soc. B 2015, 282, 20142519. [CrossRef] [PubMed]

37. Rauch, C.; Vries, J.; Rommel, S.; Rose, L.E.; Woehle, C.; Christa, G.; Laetz, E.M.; Wägele, H.; Tielens, A.G.; Nickelsen, J.; et al. Why it is time to look beyond algal genes in photosynthetic slugs. Genome Biol. Evol. 2015, 7, 2602-2607. [CrossRef] [PubMed]

38. Gustafson, D.E., Jr.; Stoecker, D.K.; Johnson, M.D.; Van Heukelem, W.F.; Sneider, K. Cryptophyte algae are robbed of their organelles by the marine ciliate Mesodinium rubrum. Nature 2000, 405, 1049-1052. [CrossRef] [PubMed]

39. Johnson, M.D. Acquired Phototrophy in Ciliates: A Review of Cellular Interactions and Structural Adaptations. J. Eukaryot. Microbiol. 2011, 58, 185-195. [CrossRef] [PubMed] 
40. Johnson, M.D.; Stoecker, D.K. Role of feeding in growth and photophysiology of Myrionecta rubra. Aquat. Microb. Ecol. 2005, 39, 303-312. [CrossRef]

41. Johnson, M.D.; Oldach, D.; Delwiche, C.F.; Stoecker, D.K. Retention of transcriptionally active cryptophyte nuclei by the ciliate Myrionecta rubra. Nature 2007, 445, 426-428. [CrossRef] [PubMed]

42. Nishihara, N.; Horiike, S.; Oka, Y.; Takahashi, T.; Kosaka, T.; Hosoya, H. Microtubule-Dependent Movement of Symbiotic Algae and Granules in Paramecium bursaria. Cell Motil. Cytoskeleton 1999, 43, 85-98. [CrossRef]

43. Harkins, K.R.; Galbraith, D.W. Factors Governing the Flow Cytometric Analysis and Sorting of Large Biological Particles. Cytometry 1987, 8, 60-70. [CrossRef] [PubMed]

44. Khan, M.F.; Unruh, T.L.; Deans, J.P. Implementation of a Flow Cytometry Strategy to Isolate and Assess Heterogeneous Membrane Raft Domains. Flow Cytometry—Recent Perspectives; Schmid, I., Ed.; InTechOpen: Rijeka, Croatia, 2012; pp. 169-184.

45. Gaurav, V.; Kolewe, M.E.; Roberts, S.C. Flow Cytometric Methods to Investigate Culture Heterogeneities for Plant Metabolic Engineering. Methods Mol. Biol. 2010, 643, 243-262. [PubMed]

46. Hörtnagl, P.H.; Sommaruga, R. Photo-oxidative stress in symbiotic and aposymbiotic strains of the ciliate Paramecium bursaria. Photochem. Photobiol. Sci. 2007, 6, 842-847. [CrossRef] [PubMed]

47. Gerashchenko, B.I.; Nishihara, N.; Ohara, T.; Tosuji, H.; Kosaka, T.; Hosoya, H. Flow cytometry as a strategy to study the endosymbiosis of algae in Paramecium bursaria. Cytometry 2000, 41, 209-215. [CrossRef]

48. Martin, W.; Rujan, T.; Richly, E.; Hansen, A.; Cornelsen, S.; Lins, T.; Leister, D.; Stoebe, B.; Hasegawa, M.; Penny, D. Evolutionary analysis of Arabidopsis, cyanobacterial, and chloroplast genomes reveals plastid phylogeny and thousands of cyanobacterial genes in the nucleus. Proc. Natl. Acad. Sci. USA 2002, 99, 12246-12251. [CrossRef] [PubMed]

49. Timmis, J.N.; Ayliffe, M.A.; Huang, C.Y.; Martin, W. Endosymbiotic gene transfer: Organelle genomes forge eukaryotic chromosomes. Nat. Rev. Genet. 2004, 5, 123-135. [CrossRef] [PubMed]

50. Okamoto, N.; Inouye, I. Hatena arenicola gen. et sp. nov., a Katablepharid Undergoing Probable Plastid Acquisition. Protist 2006, 157, 401-419. [CrossRef] [PubMed]

51. Kadano, T.; Kawano, T.; Hosoya, H.; Kosaka, T. Flow cytometric studies of the host-regulated cell cycle in algae symbiotic with green Paramecium. Protoplasma 2004, 223, 133-141. [CrossRef] [PubMed]

(C) 2017 by the author. Licensee MDPI, Basel, Switzerland. This article is an open access article distributed under the terms and conditions of the Creative Commons Attribution (CC BY) license (http://creativecommons.org/licenses/by/4.0/). 